\title{
Lessons Learned from the Cambodia Enterprise Infirmary Guidelines development process
}

Bunmey Yat

David Wofford

Follow this and additional works at: https://knowledgecommons.popcouncil.org/departments_sbsr-rh How does access to this work benefit you? Let us know!

\section{Recommended Citation}

Yat, Bunmey and David Wofford. 2018. "Lessons Learned from the Enterprise Infirmary Guidelines development process," case study. Washington, DC and Phnom Pehn: Population Council, The Evidence Project. 


\section{case study \\ LESSONS LEARNED FROM THE ENTERPRISE INFIRMARY GUIDELINES DEVELOPMENT PROCESS}

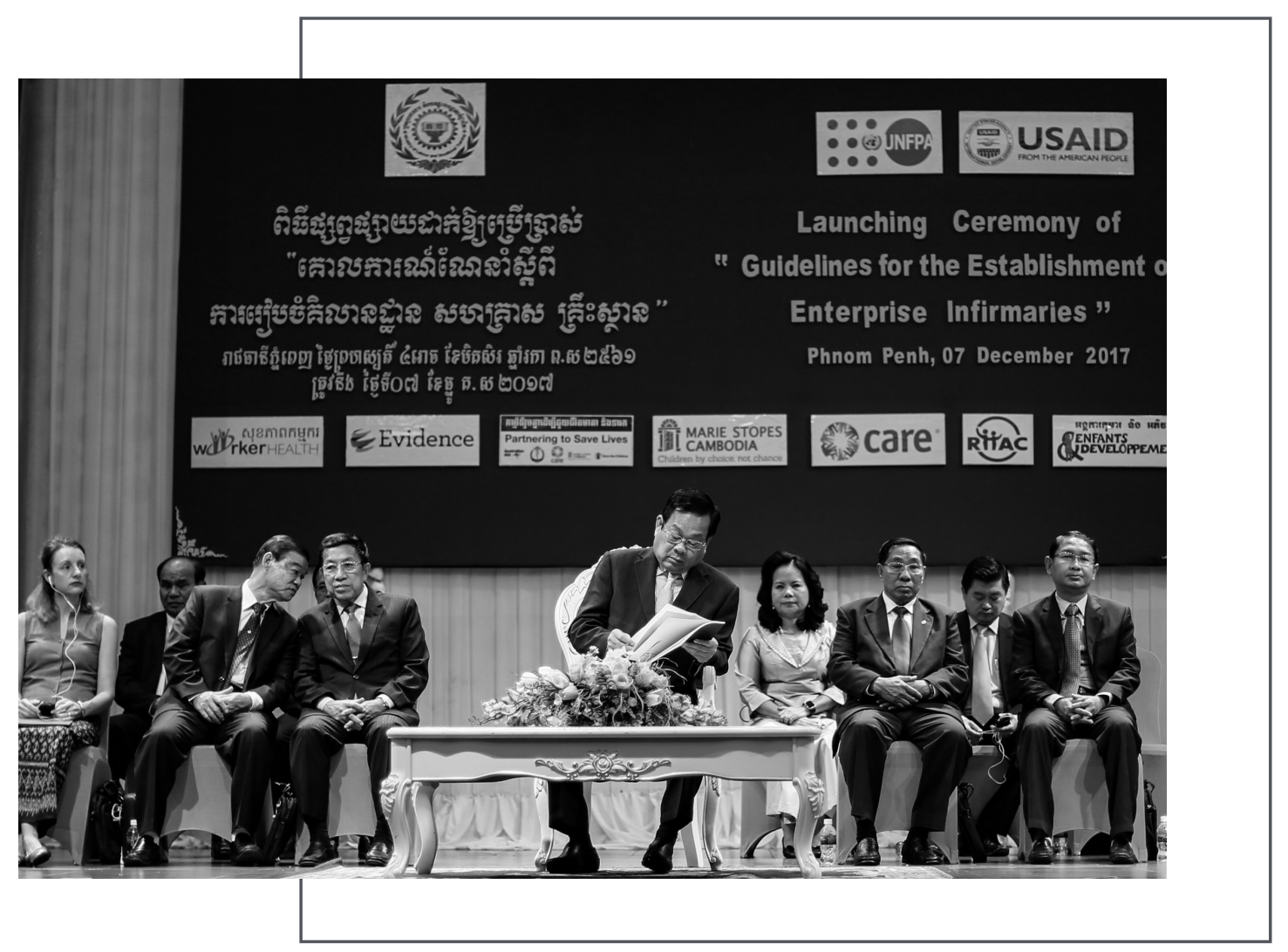

\section{KEY POLICY IMPLICATIONS FOR CAMBODIA}
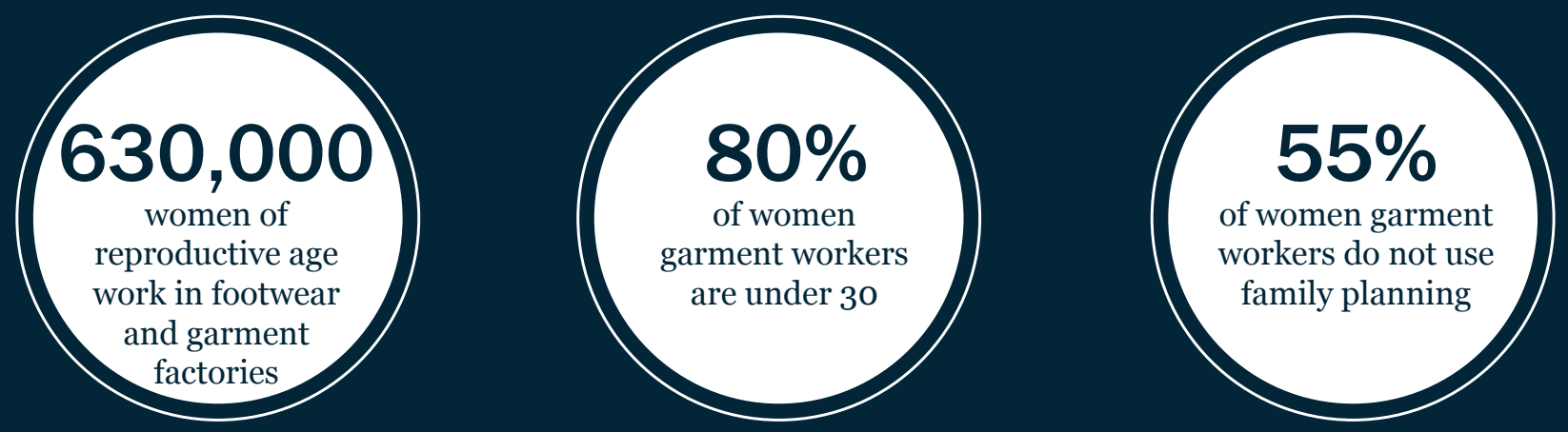


\section{overview}

\&

\section{background}

In December 2017, the Cambodian Ministry of Labor and Vocational Training (MoLVT) launched, as formal policy, a set of workplace health infirmary guidelines for enterprises. The guidelines were developed in partnership with non-governmental organizations (NGO), international agencies and donors. What made this policy process unique for Cambodia - and what can be replicated elsewhere - is that a group of organizations typically focused on public health policy successfully engaged on labor policy with a labor ministry.

The process used implementation science to elevate the importance of worker health, particularly the reproductive health of female workers, as a needed focus of occupational health and safety in garment factories and other enterprises. The guidelines were the culmination of a twoand-a-half-year policy process that included sharing evidence on the health-seeking behaviors of female garment factory workers, analyzing existing regulations, facilitating discussions with industry stakeholders, developing consensus on content and messages, and producing a guidance document.

This case study describes the policy process, which is seen by government, donors, civil society and industry as a success. The purpose is to capture learnings from the process, which was underpinned by the strategic use of evidence in decision-making. While no new regulations were developed, the guidelines made it easier for enterprises to comply with current regulations and served as a welcome tool for applying good practices for improving

concerns industry managers as productivity in the sector is low and poor health can be a contributing factor. The issue of healthy behaviors received significant attention in debates over living wage rates and the cause of fainting among workers. Research has shown that health, particularly reproductive health, was a major concern to workers themselves. According to the Partnering to Save Lives (PSL) project, one quarter of all Cambodian women between the ages of 18 and 29 worked in garment factories. Research conducted by PSL showed that 80 percent of women in a Representative from GMAC at the tripartite consultation in May 2017

infirmaries, promoting healthy behaviors and addressing women's health.

\section{lessons}

learned

\section{Begin with evidence that policy change will lead to measurable impact}

The garment industry is central to the Cambodian national economy and responsible for more than 80 percent of national export income. Young women of reproductive age comprise about 90 percent of Cambodia's footwear and apparel workforce estimated at 700,000 people. The health and wellbeing of the garment industry's workforce sample from the Phnom Penh and Kandal provinces were not using family planning, while $80 \%$ were also under the age of 30 (PSL, 2014a). Subsequent research by the Evidence Project in 2017 in the same provinces found that contraceptive use among married women garment workers is rising, bringing the overall percentage of women garment workers not using family planning to $55 \%$.

Evidence Project research (Heng et al., 2017) found that these workers faced unique barriers and facilitating factors at individual, factory and healthcare system levels, which influenced their health seeking behaviors. Despite some support from family and friends they still reported limited income and limited reproductive health (RH) and family planning (FP) education as constraints in seeking the right health services. The factory infirmaries were cited as the most accessible health providers during working 


\section{WorkerHealth}

In early 2015 USAID and UNFPA began discussions about workplace health policies and practices, including some NGO partners who had workplace experiences. Soon after, USAID launched the Cambodia Worker Health Coalition (WorkerHealth), designed to address the health needs, particularly reproductive health and voluntary family planning, of female workers in Cambodia's garment industry and expand their access to quality health services.

The Population Council, with USAID funding through the Evidence Project, and Marie Stopes International Cambodia (MSIC) jointly developed and led WorkerHealth. The Evidence Project was responsible for improving the enabling policy environment for health in factories. This would bring a range of industry stakeholders together to develop joint solutions and collective action while providing them with rigorous research and evidence of 'what works' for use by policy makers, apparel brands, NGOs, and factories. MSIC developed and implemented the workplace models for increasing access to quality-assured reproductive health services in the community. While the project would reach nearly 40,000 workers directly with interventions over two years, the broader goal was to have systemic impact through a comprehensive approach that would expand the access to quality health services and improve the well-being of the estimated 700,000 garment workers.

This approach responded to a common criticism in Cambodia that, while there had been many successful one-off projects focusing on worker health and wellbeing, none had large-scale impact and proven their sustainability. The Evidence Project situational analysis documented (see Heng and Bajracharya 2017 ) the limitations of these one-off projects. WorkerHealth, was designed to pursue policy engagement of key industry stakeholders and models of service delivery and access based on research evidence, with the goal of laying the foundation for future workplace health initiatives and collaborations that could reach the majority of workers.

hours but workers noted their limited capacity and quality. The research supported several actionable recommendations. This case study focuses on the recommendation to build the capacity of factory infirmaries, especially in reproductive health and voluntary family planning information and services.

\section{Assess the policy environment and stakeholder landscape}

The infirmary guidelines process started in a difficult context, soon after Cambodia had experienced wide-spread labor disputes and strikes that halted factory production and eventually led to increases in worker wages. The Evidence Project assessed the landscape in "Workplace Health and the Garment Sector in Cambodia" (Yat, Rodehau, and Wofford 2017), which analyzed the dynamics of different stakeholders, and their direct and indirect connections to garment worker well-being, health, and the policy landscape. The analysis showed that the Cambodia garment industry operates in a complex and challenging policy environment in which many issues are debated often with little agreement over causes, responsibilities or solutions. In January 2016, the government formally established, by sub-decree, a new health insurance scheme to extend health services to formal sector workers through the National Social Security Fund (NSSF), a legal administrative, public, and financially autonomous organization under the technical guidance of Ministry of Labour and Vocational Training and the financial tutelage of Ministry of Economy and Finance. Although initially designed as a program based on a joint contributions system, equally divided between employers and workers, it was reconfigured to become an employer-only-based contribution program in January 2018.

Factory management and industry groups expressed deep concern about the impact on Cambodia's competitiveness and factory revenues of both new wage increases and new health care costs under NSSF. Industry did not want any additional burdens, particularly related to health, placed on them. The NSSF's expansion however has been rapid. According to the NSSF's latest report in March 2018, the scheme covers approximately 1.4 million workers from 12,000 registered enterprises.

The assessment showed a challenging NGO landscape in Cambodia, like the industry context, with competition among NGOs that, at the same time, would often collaborate, especially on health-related work. Cambodian health NGOs did not have much experience in shaping labor policies or practices related to workplace health. Many NGOs implemented activities in factories or with workers in partnership with brands. Despite this experience, many industry groups and factory managers, with some notable exceptions, tended to distrust most NGOs. 


\section{Engage a \\ Government Champion}

The Royal Government of Cambodia and key agencies, the MoLVT and Ministry of Health $(\mathrm{MOH})$, were open to the idea of external organizations, in this case USAID and UNFPA, helping to review workplace health regulations and develop guidelines. His Excellency Dr. Huy Han Song, the Secretary of State of the MoLVT, championed the process, providing essential direction and support, without which the process would have floundered. The final product reflects his leadership and the positive engagement by the MoLVT technical staff.

\section{Work within a formal structure}

A Working Group comprised of technical experts of the part- ner organizations was formed under the Tripartite Coordination Committee for HIV/AIDS (TCC), a formal policy structure of the MoLVT. This gave legitimacy to the Working Group and the development of guidelines. It enabled the members of the Working Group to operate as an ad-hoc entity, under the HIV/ AIDS committee, to provide technical assistance and support to the MoLVT, including reviewing existing regulations (Prakas 139 and 300), and to develop guidelines together with the MoLVT.

\section{Promote local leadership}

Cambodians led the policy process. While all but one member of the Working Group were international organizations, the majority were represented by Cambodians, including the co-chairs and secretariat. A national consultant was engaged from a pool of Cam-

\section{Be realistic - there will be challenges}

Policy change takes time. Working Group members and the MoLVT originally envisioned a year-long process, but it took more than two years. It is challenging to consult with various external and government stakeholders with different focuses and priorities, organize participatory meetings and reach consensus. Identifying and targeting the right stakeholders in this sector had to be done carefully to assure their meaningful contribution and ownership. The process could not be rushed.

Changing occupational health regulation requires much greater consensus building and evidence dissemination. The initial work plan envisioned a process of reviewing and updating two pieces of regulation (Prakas 139 and 300) as well as developing guidelines. It soon became clear that, while the MoLVT recognized the Prakas needed updating, the timing was not right. The new employer-based health insurance scheme was just being launched. Key industry and government stakeholders needed more time to see the impact of this new law on workplaces. And they needed more understanding of and evidence for new models of integrating public health and international standards into occupational health standards that were practical, cost effective, and not burdensome.

bodian applicants. This composition enabled formal and informal meetings and contact to be held in Khmer and promoted communication and trust.

The NGO members of the Working Group were experts in health and family planning, not labor experts. Yet all had direct experience with factories and workers, having implemented such activities as building the capacity of infirmary staff, addressing sexual harassment, and expanding worker health education. Their practical factory experience gave credibility to their proposals for providing factories guidance of how to increase the quality services available to their employees.

\section{Offer solutions that are backed by evidence}

All phases of the policy process were informed by existing and ongoing research and program evaluations by Working Group members. For example, the members undertook a review of the current situation of factory infirmaries in Cambodia and other countries (Vietnam, Bangladesh, India and Indonesia), looking at services available at the infirmary, health-seeking behaviors of workers, limitation and services gaps. They discovered significant barriers that prevent workers from accessing the healthcare services and a gap between public behavior change communications efforts and infirmaries health promotion. This review also disclosed potential areas for improving the infirmary functions. WorkerHealth (see sidebar on page 3) undertook research that included a situational analysis of the stakehold- 


\section{Infirmary Guidelines Development Process}

2015

2016
July

August

September

October

November

December

January

February

March

April

May

June

July

August

September

October

November

December

2017

January

February

March

April

May

June

July

August

September

October

November

December
Advocacy for Infirmary Guidelines Development process

$\begin{array}{lll}\text { Creation of working group \& development of ToR } & \begin{array}{l}\text { Working Group Co-chairs: } \\ \text { UNFPA, USAID-(Co-chairs) } \\ \text { Secretariat: WorkerHealth } \\ \text { (Evidence Project/Population } \\ \text { Council) \& PSL (MSIC, CARE, } \\ \text { Save the Children) }\end{array} \\ \begin{array}{l}\text { Members: CARE, RHAC, PSI, } \\ \text { Initial meeting held with the MoLVT }\end{array} & \begin{array}{l}\text { E\&D, BFC } \\ \text { Inting }\end{array}\end{array}$

Evidence retrieval and synthesis
Consultant Terms of Reference (ToR) developed (May 2016)

Engagement of a national consultant Recruitment under UNFPA (June-July 2016)

MOLVT, NMCHC, WHO,

AFD, GRET, GMAC,

Brands and Factories
Consultative meetings with government on content of guidelines \& presentation of zero, first and second drafts

- Tripartite coordination committee \& final stakeholder consultative workshop for feedback and recommendations

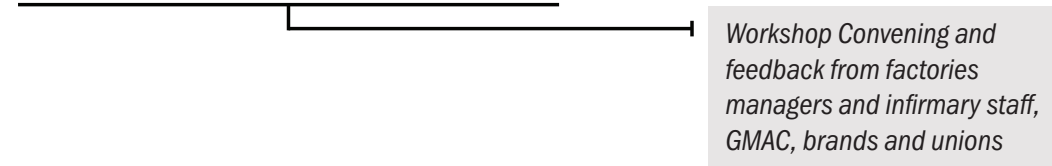

MoLVT signoff for document \& final editing, design and printing

- Approval, launch and dissemination 
er landscape, a retrospective analysis on workplace programs to date, and formative study on factories worker's health needs and issues during the process. PSL, CARE and UNFPA all contributed surveys, research and documentation of factory and migrant workers that gave support to policy proposals.

Most important was building an evidence base for workplace infirmary standards and practices that enhance compliance rather than create burdens on enterprises.

\section{Invest necessary resources, including a dedicated secretariat}

A WorkerHealth staff person, representing Population Council and its workplace policy partner Meridian Group International, Inc., led the Secretariat (with PSL). Her time was fully funded to devote to policy development in addition to the staff time each organization voluntarily contributed. The challenges of managing and coordinating a policy process required the significant time and focus of a dedicated staff person. The Secretariat accommodated different needs and requirements of stakeholders, ensured evidence-based discussions, and helped negotiate compromises that led to consensus. This combination of donated and dedicated staff time in joint planning and coordination had a significant payoff.

WorkerHealth served as a neutral party with no stake in specific policy outcomes. This was possible because the primary interest of the Population Council, as a research organization and not an implementer of programs, was in generating and disseminating evidence to be utilized by policymakers in their deliberations.

The Working Group members contributed not only staff time and expertise, but also funds to cover the cost of stakeholder consultations and technical meetings, a national consultant, and the design and printing of the guidelines. This policy process would not have succeeded without the funding that all Working Group members contributed. The direct contribution was approximately $\$ 31,000$.

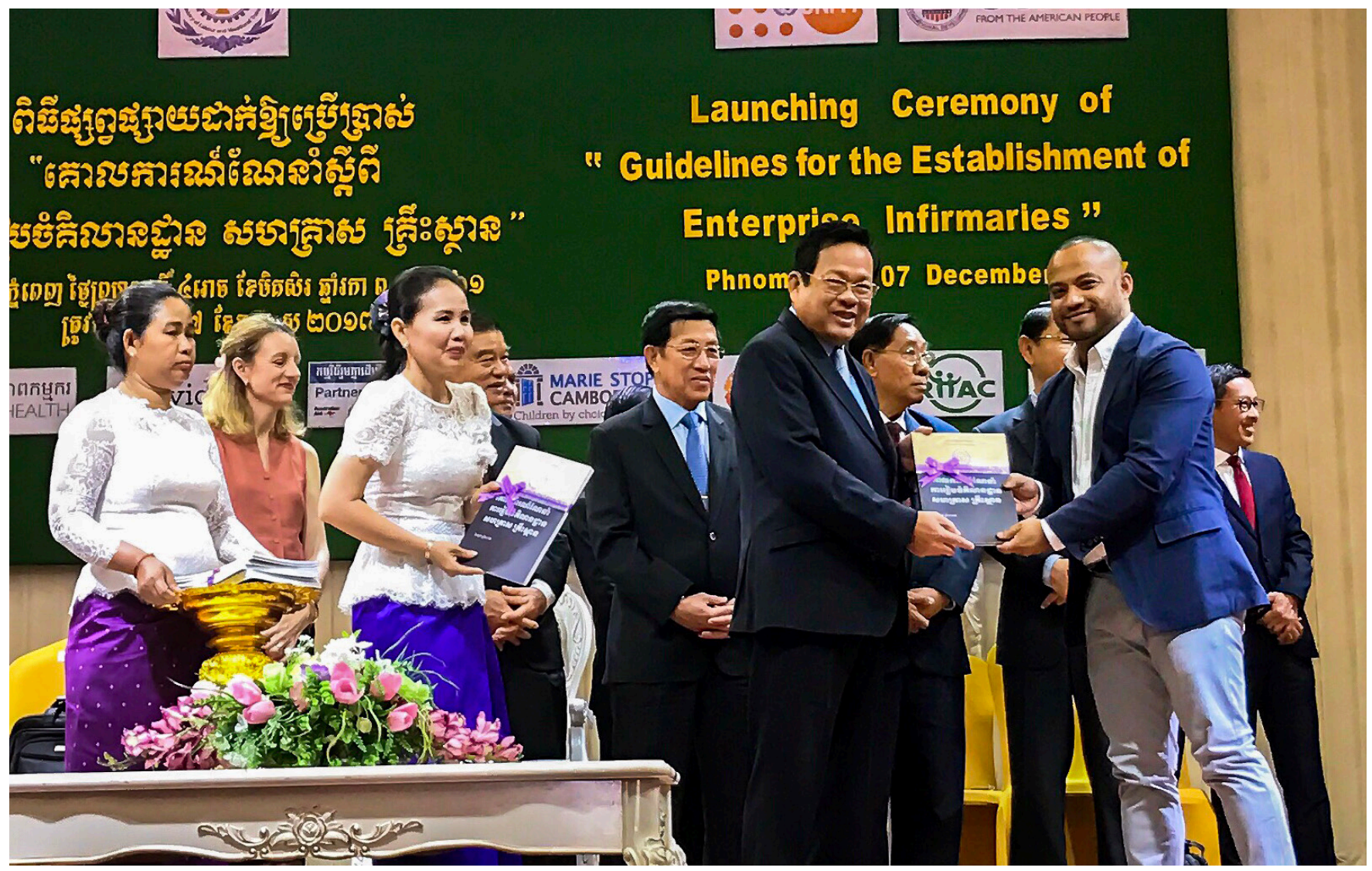

The Infirmary Guidelines was launched at a public event in December 2017 in which His Excellency Dr. Ith Samheng, the Minister of Labor and Vocational Training presided over a handover ceremony to give the guidelines to representatives of the MoLVT, trade unions, infirmary staff and national and international organizations. 


\section{Understand what compliance involves and craft policy to minimize burden}

Key government agencies (MoLVT, MoH) worked with development agencies (USAID, UNFPA, ILO/BFC), NGOs, apparel brands (Marks \& Spencer, GAP, H\&M, TESCO), industry (GMAC, CAMFEBA), union representatives, garment factories and some infirmary staff, all of whom contributed to the development of the Enterprise Infirmary Guidelines.

While many voices urged that the guidelines focus only on how to comply with existing occupational safety and health regulations, key stakeholders leveraged persuasive evidence that forged consensus around the inclusion of public health issues. Critical to forging consensus was providing the evidence base for workplace infirmary standards and practices that enhance compliance rather than create burdens.

A stakeholder workshop, in May 2017, had the dual purpose of building support and collecting feedback from relevant stakeholders who would implement the guidelines. The TCC hosted the workshop, which included two representatives each from 15 factories (a Human Resources manager and an infirmary staff), five labor unions, brands and four employers' groups as well as the MoLVT and the Working Group. This final consultation proved critical, paving the way for greater acceptance of the guidelines. The factory representatives had a range of concerns, from wanting more clarity on technical issues such as the required number of beds and contents of first aid kits to raising concern about support for management, costs, referral process, skills of infirmary staff and training on reproductive health and maternal care. Yet, overall the factory representatives said that the guidelines were a good tool for improving infirmary services and providing new information to help fill gaps in the implementation of the Prakas. One outcome of the meeting was to provide additional annexes with practical documents and tools for garment factories and infirmary teams related to referral, job descriptions , infirmary layout, patient records, and first aid kits. Several tools would enable factories to voluntarily implement additional services that go beyond occupational and safety health to improve gender health services to workers.

While the primary purpose of the guidelines was for the government to give industry direction on meeting current law, it went beyond by introducing guidance on voluntary measures proven to improve workplace health staff, services, and referrals to address the unique health needs of the clear majority of the apparel workforce: young women of reproductive age.

\section{conclusion}

The Enterprise Infirmary Guidelines represent an important achievement by the MoLVT, its partners and industry stakeholders. The guidelines addressed ways to expand voluntary services such as counselling on specific health needs of workers, particularly women, and making referrals to qualified external providers, particularly in connection to the new health insurance program. This happened because of concerted efforts to incorporate multiple perspectives, experiences and agendas into the guidelines and to build consensus.

\section{way forward}

As a highly effective, collaborative approach that brought together health, labor, and industry organizations, this process can serve as a model for collective action that strengthens both the public health and occupational health systems. And it points to good practices for utilizing and translating relevant evidence to inform policymakers and improve future policies and programs.

Much work remains to create dialogue and policy discussions between public health and occupational health and safety organizations and agencies. The Enterprise Infirmary Guidelines process indicates that research is important when new policy is the objective; there is need to provide strong evidence that impact of the policy aligns with the self-interest of the stakeholders that must abide by it. Significant evidence already exists that addressing women's and worker health can contribute to occupational health and safety compliance. Yet this evidence has not been shared widely. And more research is needed. 


\section{references}

Heng, Molyaneth and Ashish Bajracharya. 2017. "Garment Sector Health Interventions in Cambodia: A Comprehensive Review, "Research Report. Phnom Penh, Cambodia: Population Council, The Evidence Project.

PSL. (2014a). Reproductive, Maternal and Neonatal Health Knowledge, Attitudes and Practices among Female Garment Factory Workers in Phnom Penh and Kandal Provinces. Phnom Penh: Partnering to Save Lives.

Heng, Molyaneth et.al. 2017 "Health Needs, Health Seeking Pathways, and Drivers of Health Seeking Behaviors of Female Garment Factory Workers in Cambodia: Findings from a Qualitative Study in Phnom Penh and Kandal Provinces" Policy Brief, Washington DC and Phnom Penh, Cambodia: Population Council, The Evidence Project.

Yat, Bunmey, Carolyn Rodehau, and David Wofford. 2017. "Workplace Health and the Garment Sector in Cambodia. "Policy Brief. Washington, DC and Phnom Penh, Cambodia: Population Council, The Evidence Project.

\section{THE EVIDENCE PROJECT}

Population Council 4301 Connecticut Avenue NW

Suite 280

Washington, DC 20008 USA

tel +12022379400

evidenceproject@popcouncil.org

\section{CONTRIBUTORS}

Bunmey Yat David Wofford Ashish Bajracharya Karen Hardee Robin Johnson Anneka Van Scoyoc

(i) USAID

The Evidence Project is made possible by the generous support of the American people through the United States Agency for International Development (USAID) under the terms of cooperative agreement no. AID-OAA-A-13-00087. The contents of this document are the sole responsibility of the Evidence Project and Population Council and do not necessarily reflect the views of USAID or the United States Government.

Evidence

The Evidence Project uses implementation science-the strategic generation, translation, and use of evidence-to strengthen and scale up family planning and reproductive health programs to reduce unintended pregnancies worldwide. The Evidence Project is led by the Population Council in partnership with INDEPTH Network and Population Reference Bureau.

Meridian Group International, Inc. is a woman-owned, small Meridian Group International, Inc. business that works with the private and public sectors to create innovative programs and partnerships that benefit both business and society. Meridian Group International, Inc. is a partner of the Evidence Project and the Cambodia Worker Health Coalition.

Suggested Citation: Yat, Bunmey and David Wofford. 2018. "Lessons Learned from the Enterprise Infirmary Guidelines Development Process," Case Study. Washington, DC and Phnom Pehn: Population Council, The Evidence Project.

(c) 2018 The Population Council, Inc. 